\title{
0 reflexo de cursos de capacitação empreendedora por meio da capacidade absortiva em empresas de Imbituva Paraná
}

\author{
AraGrolinaVelozo Mestranda em Administração, Universidade Estadual do Centro-Oeste (UNICENTRO), \\ Brasil. carol.velozo@hotmail.com \\ JoãoFranoiscoMbrowini Doutor em Administração, Universidade Estadual do Centro-Oeste (UNICENTRO), Brasil. \\ imorozini@uol.com.br
}

\begin{abstract}
RESUMO
A capacidade absortiva é uma capacidade dinâmica que possui importância quando associada com a aquisição de novo conhecimento externo, sua assimilação e transformação juntamente com o conhecimento interno já efetivo e a exploração e desenvolvimento de conhecimentos novos. No Brasil, a educação empreendedora tem sido um ponto relevante, sendo implementada e desenvolvida por meio de programas que buscam a capacitação dos empreendedores. Assim, considera-se que é possível repassar o conhecimento de empreender, ou seja, empreender é uma ferramenta peculiar de empreendedores. Esta pesquisa foi realizada por meio do método de análise de conteúdo, com entrevistas semiestruturadas realizadas com empreendedores que foram capacitados no curso de educação empreendedora Bom Negócio Paraná. 0 estudo demonstra a relação entre a capacitação profissional e a capacidade absortiva dos empreendedores, bem como suas fases de aquisição, assimilação, transformação e exploração do conhecimento obtido. A capacitação empreendedora é incentivada pelos empresários em suas empresas, que a veem como um ponto positivo, pois conseguem aplicar o conhecimento adquirido. Por isso, é visível a presença da capacidade absortiva nos empreendedores considerando que estes conseguem, após a aquisição do conhecimento, assimilá-lo, transformá-lo e explorá-lo em sua empresa.
\end{abstract}

Palavras-chave: Capacidades Dinâmicas. Capacidade Absortiva. Educação Empreendedora.

\section{The reflection of entrepreneurial training courses through the absortive capacity in Imbituva, Paraná, companies}

\begin{abstract}
Absorptive capacity is a dynamic capacity that has importance when associated with the acquisition of new external knowledge, its assimilation and transformation with the already effective internal knowledge and the exploration and development of new knowledge. In Brazil, entrepreneurial education has been a relevant point, being implemented and developed through programs that seek the training of entrepreneurs. Thus, it is considered that it is possible to pass on the knowledge of undertaking, that is, to undertake is a peculiar tool of entrepreneurs. This research was carried out through the content analysis method, with semi structured interviews conducted with entrepreneurs who were trained in an entrepreneurial education course: Bom Negócio Paraná. The study shows the relationship between professional training and the entrepreneurs' absorptive capacity, as well as their phases of acquisition, assimilation, transformation and exploitation of the knowledge obtained. Entrepreneurial training is encouraged by the entrepreneurs, who see it as a positive action, since they can apply the knowledge acquired in their companies. Therefore, the presence of the absorptive capacity in entrepreneurs becomes visible considering that, after the acquisition of knowledge, they are able to assimilate, transform and explore it in their company.
\end{abstract}

Key words: Dynamic Capabilities. Absorptive Capacity. Entrepreneurial Education. 


\section{INTRODUÇÃO}

O empreendedorismo e a educação empreendedora são dois fatores que têm sido, nos últimos anos, de elevada importância para as empresas, pela possibilidade de ampliação da vantagem competitiva, sucesso, sobrevivência e redução de custos no mercado. Para tanto, conforme Previdelli e Sela (2006) é necessário que os empreendedores busquem oportunidades e tenham aptidão para assumir riscos, pois, segundo Uriarte et al. (2000) os empreendedores não são apenas os detentores de empresas, mas sim aqueles que além de administrá-las, criam, inovam, arriscam e crescem.

Assim, o Brasil tem trabalhado em programas de Educação Empreendedora que buscam o aumento da quantidade de jovens proativos, desenvolvendo habilidades empreendedoras, como a inovação, 0 conhecimento, a produção de projetos e a adaptação às mutações. (SCHAEFER; MINELLO, 2016) Neste sentido, as capacidades dinâmicas de uma empresa são adquiridas, principalmente buscando estabilidade e vantagem competitiva como resposta à mutabilidade e imprevisão do ambiente organizacional por meio da integração, construção e reconfiguração correta de recursos internos e externos (ESCOBAR, 2012).

Wang e Ahmed (2007) identificam três tipos de capacidades dinâmicas: capacidade adaptativa, inovadora e de absorção ou absortiva. Nesse estudo dar-se-á ênfase à capacidade absortiva, que, de acordo com Cohen e Levinthal (1990 apud GAEBLER, 2015), se refere à capacidade de identificar e explorar o conhecimento e informação do ambiente externo, assimilando-o e aplicando-o na organização. Desta forma, busca-se a resposta para a seguinte questão de pesquisa: Como o conhecimento externo influencia no desempenho organizacional dos proprietários de empresas participantes de cursos de aperfeiçoamento profissional?

O principal objetivo deste trabalho é compreender o relacionamento existente entre a capacitação profissional e a capacidade absortiva dos empreendedores. Além disso procura-se analisar como ocorre a identificação e internalização do conhecimento adquirido por meio de cursos; averiguar se há a compreensão da informação obtida pela capacidade absortiva; compreender a transformação e combinação do conhecimento existente com o conhecimento adquirido por meio da capacitação; e por fim, analisar se os empreendedores consideram viável a aplicação dos novos conhecimentos adquiridos na empresa a que pertencem.

\section{FUNDAMENTAÇÃO TEÓRICA}

Neste capítulo serão apresentados apontamentos teóricos relevantes para este estudo, nos quais são trazidas citações de autores clássicos e contemporâneos, que fundamentam o texto para posterior análise.

\subsection{Empreendedorismo}

Há uma dificuldade de conceitualização dos termos empreendedor e empreendedorismo. Empreendedorismo pode ser visto como uma base para a criação de inovações e geração de crescimento no setor econômico, e os empreendedores podem ser considerados aqueles detentores de capacidade para propor e introduzir inovações tecnológicas e gerenciais no mercado (SALES; SOUZA NETO, 2006).

Além disso, devem ser diferenciados os empreendedores dos empresários. De acordo com Uriarte et al. (2000), enquanto os empresários são os responsáveis pela administração da empresa, traçando planos e metas e delegando funções, o empreendedor precisa, além dos aspectos anteriores, inovar na organização, efetuar suas ideias, e assumir, administrar, sobreviver e conviver com os riscos que vêm de qualquer atividade organizacional. Segundo o mesmo autor, todo empreendedor é um empresário, mas o empresário só é um empreendedor quando cria, inova, arrisca e cresce.

Conforme Lazzarotti et al. (2015), o conceito de empreendedorismo tem sua origem na França, com o termo "entrepreneur", que tinha como objetivo definir aqueles que incentivam a rivalidade. Assim, o empreendedor foi conceituado como o indivíduo que assume riscos, beneficia-se de oportunidades para 
atingir lucros. Ainda de acordo com o autor, o risco de empreender está associado ao desafio, então os empreendedores enxergam a mudança como oportunidade, buscando-a, explorando-a e reagindo a ela como algo conveniente.

Segundo Previdelli e Sela (2006), no Brasil tem se ampliado muito o conceito de empreendedorismo, principalmente com o objetivo de expandir a competitividade, obter sucesso, sobreviver no mercado e reduzir os custos da organização. Assim, o mesmo autor afirma que o empreendedor pode ser visto como o detentor de criatividade, transformação, facilidade em trabalhar com o desconhecido, e capacidade de aprender com os erros. Além dessas, outra característica atribuída ao empreendedor é que este deve enxergar oportunidades onde outros enxergariam ameaças, tendo aptidão para trabalhar com situações de complexidade.

Mendes (2011) sugere que os empreendedores são perseguidores de oportunidades e que essas oportunidades estão correlacionadas com três variáveis decisivas que influem o pensar do empreendedor e que se relacionam com a capacidade empreendedora: inovação, proatividade e tomada de risco. De acordo com Teixeira (2012), o empreendedorismo pode adquirir a noção de inovação e os empreendedores podem ser vistos como criadores de valor, pois passam a assumir riscos a partir do momento em que adotam uma postura inovadora, e deslocam recursos de áreas de baixa produção para outras com alta produção.

A Comissão Europeia (2006, apud Mendes 2011, p. 20) nos diz que: "Empreendedorismo é um processo dinâmico e social, no qual indivíduos, sozinhos ou em colaboração, identificam oportunidades para a inovação e atuam sobre isso, transformando ideias em atividades práticas e focalizadas, seja num contexto social, cultural ou econômico".

O empreendedorismo pode surgir, tanto por meio da identificação de uma oportunidade, como também a partir do desemprego, emprego precário etc. (TEIXEIRA, 2012) Neste sentido, Cruz, Forner e Libermann (2006) afirmam existem empreendedores que empreendem por necessidade (motivados pelo desemprego) e os que empreendem por oportunidade (motivados pelo ambiente favorável), que, para os autores, são a maioria.

Sales e Souza Neto (2006) asseguram que o empreendedorismo brasileiro passa a existir, principalmente, devido à necessidade por parte dos desempregados, ou seja, estes criam uma empresa por não conseguirem obter emprego regular no mercado. Assim, conforme os mesmos autores, a principal causa para o alto desperdício de capital e para o despreparo dos empreendedores no Brasil é devido ao fato de estes terem iniciado seus negócios pela falta de opção, sem terem capacitação.

\subsubsection{Educação Empreendedora}

A educação empreendedora tem sido um aspecto relevante, sendo colocada em pauta em debates de vários países, inclusive no Brasil. A Unesco (Organização das Nações Unidas para a Educação, a Ciência e a Cultura) vem auxiliando na implementação e desenvolvimento de programas de educação empreendedora, $\mathrm{e}$ recomendando, para os estudantes, o desenvolvimento da habilidade de inovação, conhecimento, desenvolvimento de projetos e adaptação às mutabilidades, o que auxilia na ampliação do número de jovens proativos e inovadores (SCHAEFER; MINELLO, 2016).

Tendo em vista a intensidade da conceituação de empreendedorismo, Teixeira (2012) afirma que é possível visualizar que indivíduos que se favorecem da educação empreendedora conseguem adquirir e desenvolver habilidades empreen dedoras. Desta forma, a autora define a educação empreendedora conforme três diferentes níveis de educação: ensino primário, ensino secundário e ensino terciário. Dos três níveis, destaca 0 primeiro e 0 segundo por serem semelhantes ao Plano Nacional de Educação para 0 Empreendedorismo (PNEE). Sendo assim, o nível primário busca a promoção de criatividade, autonomia e iniciativa, desenvolvendo uma atitude empreendedora; e o nível secundário além de qualidades pessoais é voltado para o desenvolvimento da autoempregabilidade.

De acordo com Drucker (1985), empreender é algo possível de se repassar às outras pessoas, ou seja, não é algo congênito, uma capacidade ou dom, mas sim uma ferramenta peculiar de empreendedores. Assim, empreender é um processo por meio do qual os indivíduos enxergam uma oportunidade em ambientes em mudança. Neste sentido, Previdelli e Sela (2006) afirmam que os empreendedores devem estar aptos a 
procurar informações que os auxiliem no acompanhamento das mutações do mercado e adaptação da empresa às novas exigências. Essas informações podem ser obtidas tanto por meio da prática empresarial quanto por meio de publicações, cursos ou conselhos de profissionais que já trabalham na área.

Ainda neste sentido, Cielo (2006) coloca que existem atributos e comportamentos que são essenciais para o empreendedor e o sucesso de um empreendimento, que envolvem talento, conhecimento e persistência, para que a empresa, além de sobreviver, possa crescer e prosperar no mercado. Assim, o conhecimento é visto como fator preponderante no mercado, pois os empresários adimplentes são os que possuem maior nível de conhecimento, comparados aos inadimplentes, e isso quer dizer que, para que as atividades empreendedoras sejam prósperas, é necessário, além de motivação, conhecimento técnico, comercial e formação complementar.

Por meio da qualificação, é possível que o empreendedor reoriente sua maneira de gerir, tendo um maior planejamento de suas ações e avaliando os riscos, pois a orientação empreendedora potencializa as suas características empreendedoras. (CRUZ; FORNER; LIBERMANN, 2006)

Assim, ainda de acordo com Cruz, Forner e Libermann (2006) realizaram um estudo no qual foi identificado que as empresas, ainda que novas e nascentes, que possuem gestores que participaram de um programa de capacitação têm maiores chances de sobrevivência no mercado. Assim, afirmam que os participantes de programa de capacitação obtiveram maiores retornos econômico-financeiros em suas organizações após a realização do curso.

\subsection{Capacidades Dinâmicas}

O conceito de capacidades dinâmicas foi construído a partir de uma condição limitante da Visão Baseada em Recursos, principalmente com relação à volatilidade e turbulência do ambiente organizacional, passando a ser considerado uma complementação da VBR (ESCOBAR, 2012). De acordo com Wernerfelt (1984) o principal objetivo da VBR é, por meio de recursos controlados internamente e de análise do mercado e recursos dos concorrentes, gerar a sustentabilidade competitiva.

Nos recursos empresariais incluem-se todos os ativos, capacidades, processos organizacionais, atributos empresariais, informações, conhecimentos etc. controlados pela firma que habilita a empresa para conceber e implementar estratégias que melhoram a eficiência e a eficácia. Essas numerosas possibilidades de recursos empresariais podem ser convenientemente classificadas em três categorias: Recursos de capitais físicos (tecnologia, planta da empresa, equipamentos, localização e matéria-prima), Recursos de capital humano (treinamento, experiência, reputação, inteligência, relacionamentos, e insights de gerentes e trabalhos da empresa), e Recursos de capital organizacional (relatórios formais da empresa, planejamento formal e informal, sistema de controle e organização, bem como o relacionamento informal entre grupos dentro da empresa) (BARNEY, 1991, tradução nossa).

Assim, o conceito de capacidades dinâmicas busca a explicação sobre como a vantagem competitiva é desenvolvida e mantida a longo prazo em ambientes com mudanças rápidas e imprevisíveis. As capacidades dinâmicas passaram a ser vistas como a habilidade e capacidade de integração, construção e reconfiguração dos recursos internos e externos que, quando exploradas de maneira correta, podem auxiliar na manutenção do desempenho no ambiente, mesmo com constantes mudanças. Neste sentido, a elaboração do conceito de capacidade dinâmica foi realizada com o objetivo de fornecer o dinamismo necessário à Visão Baseada em Recursos, tendo, além do foco nos recursos e capacidades, a análise dos atributos de um ambiente mutável (TEECE; PISANO; SCHUEN, 1997)

De acordo com Meirelles e Camargo (2014) o termo Capacidades Dinâmicas é uma tradução aproximada da expressão, em inglês, Dynamic Capabilities. Assim, a definição de capacidades dinâmicas pode ser considerada como a habilidade empresarial de integrar, construir e reconfigurar competências em ambientes mutáveis.

Wang e Ahmed (2007) definem a capacidade dinâmica como a orientação do comportamento organizacional que busca integrar, reconfigurar e os recursos e capacidades, aprimorando e reconstruindo-os como resposta às variações do ambiente, para alcançar vantagens competitivas. Essas capacidades 
normalmente são peculiares da empresa e são desenvolvidas no decorrer do tempo por meio de relações complexas entre os recursos da organização. Esses recursos são a base da empresa e das suas capacidades por isso podem ser definidos como elementos de "ordem zero" de uma empresa.

Teece, Pisano e Shuen (1997) referem-se às capacidades dinâmicas como a capacidade de atingir novos modos de vantagem competitiva. Dessa forma, o termo "dinâmico" é definido como a capacidade de renovar as habilidades alcançando uma concordância entre a empresa e o ambiente mutável; e o termo capacidade realça a função do gerenciamento estratégico na adaptação, integração e reconfiguração adequada dos recursos internos e externos para adequar-se ao ambiente em mudança.

As capacidades de uma empresa podem ser divididas em capacidades de primeira ordem (capacidade de implantar recursos para atingir o objetivo desejado), segunda ordem (integração de recursos à luz da direção estratégica de uma empresa) e terceira ordem (constante busca por parte da empresa da renovação, reconfiguração e recriação de recursos, recursos e recursos essenciais para abordar a mudança ambiental). Ao contrário do que afirmam Teece, Pisano e Shuen (1997) as capacidades dinâmicas são aquelas definitivas e propícias ao desempenho a longo prazo (WANG; AHMED, 2007)

Ainda de acordo com Wang e Ahmed (2007), as capacidades dinâmicas podem ser distintas e específicas quando comparadas entre uma empresa e outra, e as características comuns podem ser identificadas. Sendo assim, identificam-se três tipos de capacidades dinâmicas, por meio dos quais identificase a maneira pela qual a empresa vincula seus mecanismos às vantagens competitivas do mercado, a saber, capacidade adaptativa, capacidade inovadora e capacidade de absorção.

\subsubsection{Adaptativa}

Devido às constantes mudanças no mundo, é necessária uma adaptação contínua e flexibilidade estratégica para que uma empresa possa tornar-se competitiva. Assim, a capacidade de adaptação é considerada como uma estratégia organizacional para manter-se competitiva no mercado, ou seja, adquirir vantagem competitiva, por meio da modificação, reconfiguração e interligação dos seus recursos, capacidades e competências (KAEHLER et al., 2014). De acordo com o mesmo autor, as empresas buscam aumentar suas ações e opções estratégicas para adaptar-se ligeiramente ao determinismo e às mutações ambientais.

Ainda nessa perspectiva, Wang e Ahmed (2007) colocam que a capacidade adaptativa é conceituada como a capacidade de uma empresa em identificar e capitalizar as oportunidades presentes no mercado. Estrategicamente, a capacidade adaptativa pode ser demonstrada por meio da flexibilidade estratégica dos recursos empresariais, ou seja, a flexibilidade que está contida tanto nos recursos disponíveis e quanto na aplicação destes recursos. Além disso, os autores concordam que é necessária a capacidade de adaptar-se às mudanças ambientais para a evo lução e sobrevivência da organização na indústria e desta forma, as empresas que têm graus elevados de capacidade adaptativa possuem capacidades dinâmicas.

\subsubsection{Inovação}

O ambiente dinâmico e a competitividade dentro e fora da indústria estão forçando as empresas a colocarem maior ênfase nas atividades de inovação. A inovação é considerada como a principal fonte de competitividade e vantagem competitiva, assim, pode ser vista também como a mudança que ocorre em uma empresa em resposta à mutação dos ambientes interno e externo, bem como pode ser utilizada como prevenção visando influenciar o meio ambiente (BREZNIK; HISRICH, 2014)

A capacidade de inovação pode ser compreendida como a habilidade da organização em retirar conhecimento por meio do desenvolvimento dos procedimentos presentes na rotina da empresa e das atividades inovadoras realizadas. 0 processo de inovação é determinado pela liderança e influenciado pelos recursos disponibilizados, sistemas e ferramentas utilizadas pela gestão. Por outro lado, este processo também pode ser visto como uma função que quando desempenhada possui como apoio a cultura organizacional, a 
qual se refere à gestão do conhecimento, estilo gerencial e liderança, recursos, estrutura organizacional, estratégia corporativa e tecnologia (VALLADARES; VASCONCELLOS; DI SERIO, 2014).

De acordo com Breznik e Hisrich (2014), a capacidade de inovação é o potencial para o desenvolvimento de novos projetos, reconhecimento de oportunidades no mercado e implementação de inovações, melhorando os recursos e capacidades que a empresa já possui. Ainda segundo os autores, a capacidade de inovação se refere à capacidade de transformar conhecimentos e ideias em novos produtos que beneficiam a empresa, e para que a inovação seja produzida continuamente, é necessário adicionar mais conhecimento aos já existentes.

Wang e Ahmed (2007) afirmam que a capacidade de inovação é a capacidade de uma empresa gerar novos produtos ou mercados, coordenando a orientação estratégica conforme os comportamentos e processos inovadores. Quanto mais inovadora é uma empresa, mais capacidade dinâmica ela possuirá, assim, a capacidade inovadora de uma empresa em indústrias é um fator que deve ser levado em conta para a evolução e sobrevivência no mercado, considerando a concorrência e as mudanças do ambiente.

\subsubsection{Capacidade absortiva}

A Capacidade absortiva teve seu início na macroeconomia e seu significado foi primeiramente atribuído à capacidade de identificar, absorver, incorporar e explorar o conhecimento do ambiente e reconhecer o valor de uma informação externa, assimilando-a e aplicando-a na organização. (COHEN; LEVINTHAL, 1990 apud GAEBLER, 2015)

Para Barreto (1992), a fase de absorção do conhecimento engloba quatro fases: conhecimento, credibilidade, avaliação e absorção. Conforme 0 autor, a fase do conhecimento implica em descobrir um novo modo de agir, posteriormente é necessário acreditar que é um método eficaz, em seguida vem a fase de avaliação dos fatores decorrentes da mudança, ponderando sua vantagem relativa, sua acessibilidade, a compatibilidade com os métodos utilizados, a divisibilidade e a complexidade do novo método.

Zahra e George (2002), relatam que esta forma de capacidade dinâmica é utilizada por pesquisadores, para analisar os diversos, significativos e complexos fenômenos organizacionais; e sua importância vem sendo percebida nos campos da gestão estratégica, gestão tecnológica, negócio internacional e economia organizacional. Com o objetivo de definir o construto de Capacidade Absortiva, esses autores desmembraram e ampliaram o conceito de capacidade de absorção, destacando que além de ser reconhecida, a informação externa deve ser incorporada e transformada antes de ser explorada. Essa transformação se refere ao aprimoramento dos hábitos empresariais que auxiliam na combinação entre o conhecimento interno e externo. Assim, foram incorporadas as etapas de reconhecimento, assimilação e aplicação e acrescentada a transformação como mais um componente do construto (CRUZ, 2011).

Neste sentido, Picoli e Takahashi (2013), afirmam que pesquisas empíricas ap rimoraram o conceito de capacidade absortiva proposta por Zahra e George, as quais garantem que esta capacidade pode ser definida por meio de quatro componentes, conforme exposto no Quadro 1. 
Quadro 1 - Dimensões da Capacidade de Absorção

\begin{tabular}{|c|c|c|}
\hline Dimensão & Componente & Definição \\
\hline \multirow{2}{*}{$\begin{array}{l}\text { Capacidade de } \\
\text { Absorção } \\
\text { Potencial }\end{array}$} & Aquisição & $\begin{array}{l}\text { É a capacidade da organização para localizar, identificar, avaliar e } \\
\text { adquirir conhecimento externo considerado importante para o } \\
\text { desenvolvimento de suas operações. }\end{array}$ \\
\hline & Assimilação & $\begin{array}{l}\text { É a capacidade da organização em compreender o conhecimento (ou } \\
\text { informação) advindo de fora da empresa. Trata-se, portanto, da } \\
\text { habilidade para analisar, classificar, processar, interpretar e, } \\
\text { ultimamente, internalizar e entender o conhecimento. }\end{array}$ \\
\hline \multirow[t]{2}{*}{$\begin{array}{l}\text { Capacidade de } \\
\text { Absorção } \\
\text { Realizada }\end{array}$} & Transformação & $\begin{array}{l}\text { É a capacidade da organização em facilitar a transferência e } \\
\text { combinação do seu conhecimento anterior como novo } \\
\text { conhecimento adquirido e assimilado. Consiste em adicionar ou } \\
\text { eliminar conhecimento, interpretar e combinar o conhecimento } \\
\text { existente de uma nova e diferente maneira. }\end{array}$ \\
\hline & Exploração & $\begin{array}{l}\text { É a capacidade da empresa incorporar o conhecimento adquirido, } \\
\text { assimilado e transformado em suas operações e rotinas para a } \\
\text { aplicação e uso organizacional. Esta capacidade dará origem à } \\
\text { criação ou melhoria de um bem, sistemas, processos, formas } \\
\text { organizacionais e competências. }\end{array}$ \\
\hline
\end{tabular}

Fonte: Picoli E Takahashi (2013, p. 4).

Assim, a aquisição pode ser vista como uma forma de conexão com o ambiente e uma habilidade que a empresa possui em identificar e adquirir novos conhecimentos por meio de fontes externas (OLIVEIRA, 2016). Ainda conforme 0 autor, a atividade de assimilação é composta pelos processos de certificação da organização na análise, interpretação e compreensão sobre como o conhecimento externo pode ser utilizado em suas rotinas. Posteriormente, a empresa determina os esforços necessários para a transformação e exploração do conhecimento externo, ou seja, a empresa precisa combinar os conhecimentos internos e externos, chegando à um novo conhecimento por meio da reinterpretação dos conhecimentos já adquiridos e assimilados e, por fim, refiná-los para que sejam aplicados na empresa. Essas duas últimas fases são consideradas como as atividades da Capacidade Absortiva Realizada (OLIVEIRA, 2016).

De acordo com Wang e Ahmed (2007), a capacidade de absorção pode ser percebida na empresa por meio de alguns aspectos: compromisso a longo prazo perante o ambiente incerto; aprender, estudar, testar e desenvolver conhecimentos novos sobre tecnologias recentes; analisar a nova tecnologia cuidadosamente; desenvolver e utilizar tecnologias complementares; e possuir um alto nível de conhecimento e habilidade para aplicação de nova tecnologia. Além disso, salienta-se que a capacidade de absorção é um fator significativo em várias indústrias quando há aquisição de conhecimento externo e novo sendo assimilado juntamente com o conhecimento interno já efetivo e desenvolvimento de conhecimentos novos. Dessa forma, quanto maior a capacidade de absorção de uma empresa, mais capacidade dinâmica ela apresenta.

Ainda, concordando com o exposto por Gaebler (2015), Schleimer e Pedersen (2013), definem a capacidade de absorção como a capacidade de reconhecimento do valor de conhecimentos recentes, com a finalidade de assimilá-los e aplicá-los. Eles argumentam que a capacidade subsidiária de absorver uma nova estratégia de marketing é uma construção latente composta por três fatores: reconhecimento de valor, assimilação e aplicação (SCHLEIMER; PEDERSEN, 2013) .

\section{METODOLOGIA}

Para a realização desse estudo foi utilizada a abordagem qualitativa, por meio do método descritivo. A pesquisa qualitativa começa por meio da atenção em interesses que vão obtendo forma com o desenvolvimento da pesquisa, sem ter como finalidade a medida de dados. A pesquisa qualitativa procura 0 entendimento de fenômenos conforme o ponto de vista dos indivíduos que são parte do estudo. Os dados descritivos sobre pessoas, lugares, e processos são alcançados por meio da relação direta entre o pesquisador e o caso estudado (GODOY, 1995) 
Conforme Silva, Gobbi e Simão (2005), a pesquisa qualitativa é utilizada se busca a captação do significado dos acontecimentos e interações para os indivíduos presentes em determinados casos. 0 método de estudo descritivo envolve fatores gerais de um contexto social, e proporciona uma análise em que é possível identificar e explicar diferentes fenômenos, suas causas e efeitos, possibilitando o entendimento do comportamento dos componentes que possuem influência em determinada situação (OLIVEIRA, 1997).

A análise dos dados coletados se utilizará da técnica de análise de conteúdo. De acordo com Silva, Gobbi e Simão (2004), esta forma de análise foi usada desde as primeiras tentativas humanas de interpretar escritos, e como método, nasce objetivando a compreensão da construção de sentido que os atores sociais exteriorizam no discurso. Assim, a análise de conteúdo é baseada como método de análise do discurso que foi declarado pelos sujeitos. Bardin (2011) afirma que a análise de conteúdo é um conjunto de análise de comunicações. Flick (2009) relata que a análise de conteúdo é um procedimento clássico de análise de material textual.

Como categorias de análise dos dados foram utilizadas as seguintes: aquisição, assimilação, transformação e exploração de conhecimento. De acordo com Zahra e George (2002) esses são componentes da Capacidade de Absorção, e podem auxiliar na análise da pesquisa. Assim, Carlomagno e Rocha (2016) as categorias de análise, necessitam ter uma limitação clara, serem excludentes reciprocamente, homogêneas, por meio delas deve haver a possibilidade de esgotar o conteúdo e objetividade na sua classificação.

Serão utilizadas entrevistas semiestruturadas como técnica de análise de dados, juntamente com diário de pesquisa. Duarte (2004) relata que a entrevista é um instrumento de coleta de dados que pode ser aplicado com menos rigor do que o desejável, porém quando bem desempenhada, possibilita ao pesquisador angariar sinais sobre como cada sujeito nota e dá sentido a determinada realidade. A modalidade de entrevista semiestruturada é formada por roteiro de perguntas formuladas previamente, porém flexíveis permitindo que o entrevistador as ordene e formule novas questões, quando conveniente, durante a entrevista. (GODOI; MATTOS, 2010)

Com relação ao diário de pesquisa, Araújo et al. (2013, p. 54) relatam que:

O diário também é utilizado para retratar os procedimentos de análise do material empírico, as reflexões dos pesquisadores e as decisões na condução da pesquisa; portanto ele evidencia os acontecimentos em pesquisa do delineamento inicial de cada estudo ao seu término.

Assim, o diário de pesquisa é um método de documentação por meio do qual o pesquisador anota o processo de abordagem em campo, as experiências, problemas, fatos importantes ou fatos que foram perdidos, além de circunstâncias notadas pelo pesquisador e que podem ser úteis para o processo de reflexão do pesquisador (FLICK, 2009).

\section{ANÁLISE DOS DADOS}

Foram realizadas entrevistas com quatro empreendedores que possuem pequenas empresas de diferentes ramos do mercado, os quais realizaram o curso de educação empreendedora Bom Negócio Paraná em Imbituva - PR. As entrevistas foram realizadas no perío do de agosto a setembro de 2017, por meio de um roteiro de perguntas semiestruturadas, elaboradas com base no referencial teórico apresentado anteriormente, que foram gravadas e posteriormente transcritas para a análise. Destes entrevistados, um deles possui um consultório de odontologia, que conta com três cirurgiões-dentistas; outro entrevistado é proprietário de uma borracharia, que possui seis funcionários sendo cinco borracheiros e um assistente administrativo; 0 terceiro entrevistado é do comércio de motos e tem seis funcionários em sua empresa, dentre eles: um responsável pelo administrativo, um por compras, dois por vendas, uma pessoa no estoque e um mecânico; e por fim, o último entrevistado foi um empresário do setor de motosserras, que conta com duas pessoas trabalhando em seu estabelecimento: um mecânico e um atendente. 


\subsection{Aquisição}

A cultura organizacional das empresas pesquisadas é sempre aberta a mudanças em suas rotinas, que otimizem e melhorem as suas atividades buscando a adaptação ao ambiente incerto. No entanto, verifica-se que acabam sempre por trabalhar da mesma forma, pois justificam que cada trabalhador possui a sua atividade fixa, influenciando no mantimento do serviço de acordo com a rotina: "devido às constantes mudanças de mercado sempre buscamos nos atualizar e se adaptar para não ficarmos fora da competição do mercado" (Entrevistado 3).

Os treinamentos e cursos de aperfeiçoamento profissional são sempre estimados pelos empreendedores, de forma que, em sua maioria, incentivam aos seus funcionários, sempre que possível, a realização de novos cursos, especializações e capacitações. Porém, em uma das empresas essa atividade não é incentivada, ficando a critério do próprio funcionário a busca pela capacitação e qualificação profissional. Além disso, nenhuma das organizações entrevistadas realizou investimento em atividades de pesquisa e desenvolvimento, visando obter maiores conhecimentos empresariais. Este fato justifica-se pelo pequeno porte das empresas, que inviabiliza esta forma de investimento.

Com relação a procura, por parte da empresa, por informações externas que sejam relevantes para o negócio, destacam-se, sobretudo, àquelas pesquisas realizadas por meio do próprio cliente, por meio de conversas e indagações so bre a satisfação com o produto, o profissional e o serviço. Além disso, os empresários buscam atualizarem-se por meio de artigos relacionados ao ramo, sites, especializações e cursos profissionalizantes e de capacitação profissional, buscando sempre o aperfeiçoamento das funções empresariais. Isto ocorre, principalmente, pela necessidade constante de atualizarem-se na tecnologia, nos preços de mercado e nos lançamentos futuros de diferentes produtos.

\subsection{Assimilação}

As empresas analisadas, a partir da percepção dos empresários, procuram sempre valorizar as atitudes inovadoras e que resultam em mudanças internas, tomadas pelos seus funcionários, ainda que sejam escassas, especialmente aquelas com relação ao tratamento destinado ao cliente e à organização, limpeza e administração do ambiente de trabalho, segundo relato de dois dos entrevistados:

No meu consultório eu valorizo as atitudes que os dois cirurgiões-dentistas têm, além de mim, eles têm um bom manejo com os pacientes, têm um bom atendimento, eles dão bastante importância para o que o paciente conta, o que ele conversa, até a atitude de finalizar o tratamento, desde o cumprimento quando ele chega no consultório (Entrevistado 1).

Sempre que possível buscamos mudar de alguma forma, ou seja, melhorar a aparência, como por exemplo: os uniformes, a estrutura dentro da loja, ou outro exemplo, organizar nosso estoque quando vai aumentando a quantidade de itens estocados. (Entrevistado 3).

O conhecimento proveniente de outras empresas muitas vezes é observado e implementado pelos empreendedores, especialmente quando esse conhecimento vem a agregar no conhecimento já existente. Assim, toda a atividade realizada, bem como marcas de qualidade utilizadas por outras empresas, muitas vezes, são vistas como base para as atividades das empresas pesquisadas. Entretanto, nem sempre podem ser consideradas como fundamento, conforme exposto por um dos empresários: “A empresa já se baseou, sim, em lojas maiores do mesmo ramo, da mesma marca, e mesma revenda. Assim como já percebi que tinham coisas que eu tinha aperfeiçoado melhor do que essas próprias lojas maiores." (Entrevistado 4).

De acordo com os entrevistados, todos os funcionários, e inclusive os gerentes, são sempre qualificados de acordo com as suas funções, para que consigam exercê-la com qualidade e de forma adequada: "Os cirurgiões-dentistas do meu consultório, assim como eu, temos graduação em odontologia e somos todos especialistas, cada um na sua área” (Entrevistado 1). "Todos os funcionários têm qualificação pra exercer a função de borracheiro e a gente sempre tem mais um, junto, como se fosse um trainee, pra ir aprendendo 0 
serviço" (Entrevistado 2). "Sim (são todos qualificados), sempre que possível fazendo curso de qualificação profissional" (Entrevistado 3). "O funcionário tem curso na área de mecânica (...), e eu na frente (atendendo) ainda não tenho uma formação acadêmica, que seria na área de administração pra empresa, mas sempre estou fazendo algum tipo de curso" (Entrevistado 4).

Os conhecimentos advindos dos cursos de capacitação são facilmente identificados e visualizados na prática empresarial, como algumas funções básicas repassadas em sala de aula e que podem ser utilizadas na rotina da empresa. Isso acontece porque os cursos presenciados por eles foram dinâmicos, de forma a demonstrar com exemplos práticos o que deveria ou não ser feito para que a empresa obtivesse sucesso.

Eu achei fácil de identificar justamente porque eles vieram explicados de forma prática, o que eu gostei mais é que o assunto era explicado por meio de exemplos de empresas que já tinham dado certo, já tinham usado, já tinham colocado em prática, então foi o que eu achei mais interessante no curso de capacitação. (Entrevistado 4).

Neste sentido, os conhecimentos adquiridos deixam de ser bons apenas na teoria, e passam a ser interessantes também na prática, pois são facilmente assimilados pelos empreendedores, devido à forma como são repassados. Alguns dos assuntos mais facilmente assimilados pelos entrevistados foram o cálculo do custo fixo, custo variável, e preço de venda, que além de auxiliar na formação de valor da mercadoria, auxiliam também na estimativa do valor gasto mensalmente.

\subsection{Transformação}

Considerando a transformação como a capacidade da organização em reconhecer e combinar os conhecimentos internos e externos, chegando a um novo conhecimento compatível com as atividades da empresa (OLIVEIRA, 2016), foi possível visualizar que os empreendedores que participaram de cursos de capacitação buscaram repassar e combinar o conhecimento já adquirido e assimilado com os demais funcionários, sócios ou gerentes da empresa em que trabalham, transformando-os em uma forma de conhecimento mais completa. Esses pensamentos são compartilhados e divididos entre a organização, normalmente por meio de conversas e diálogos informais ou pequenas reuniões, buscando sempre melhorar 0 ambiente empresarial.

Na maioria dos casos busca-se o repasse das informações importantes obtidas na capacitação, ainda que entre chefe e funcionário, explicando por meio de planilhas, demonstrações de cálculo e diálogos, qual a melhor forma de se trabalhar determinada função na empresa. Entretanto, esta pode ser uma tarefa difícil para alguns empresários, que não possuem essa facilidade em transferir de maneira correta aquilo que compreenderam no curso, retendo o conhecimento em apenas uma pessoa da empresa.

Quando visualizada a importância do assunto tratado no curso, a melhoria que este pode trazer para o negócio, e a sua facilidade de assimilação, os participantes procuram incorporá-lo à organização para aprimorar as atividades já realizadas, melhorar 0 atendimento ao cliente e 0 ambiente organizacional. Assim, explicitou-se que os conhecimentos adquiridos e assimilados pelos participantes por meio da capacitação empreendedora, quando verificada a sua viabilidade prática, são combinados com os conhecimentos já existentes anteriormente e transformados em um novo conhecimento.

\subsection{Exploração}

A exploração do conhecimento consiste na capacidade da empresa em apurar, expandir e alavancar as aptidões já existentes, além de produzir novos recursos. Assim, é unânime que o conhecimento obtido por meio do curso de capacitação auxilie na inovação e melhoria nos produtos e serviços das empresas analisadas, pois de acordo com os entrevistados, os cursos ajudam no crescimento e evolução dos participantes como trabalhadores e desta forma buscam oferecer serviços novos, melhores e mais adequados aos seus clientes. Por meio da exploração do conhecimento, é possível melhorar as estratégias da empresa, como por exemplo, 
o marketing empresarial. Além disso, o conhecimento já transformado torna possível a atualização da empresa com relação a novas formas de trabalhar, aquisição de novas concepções, e adaptação ao ambiente em constante mutação, e, desta maneira, fica mais fácil manter-se à frente dos concorrentes.

A exploração do conhecimento adquirido em cursos, nem sempre é de fácil realização, pois muitas vezes o que se vê na teoria se torna de difícil visualização na realidade da organização. Porém, a maioria dos empreendedores procura a incorporação na sua empresa, pois consideram que de nada vale a obtenção do conhecimento sem colocá-lo em prática. Essa exploração ocorre, normalmente, buscando melhorar um determinado ponto da empresa, onde se vê uma maior precariedade, ou seja, utiliza-se para a melhoria em algum setor da empresa.

Neste sentido, se o conhecimento for aplicável na empresa e trouxer melhorias significativas, os empreendedores buscam incorporá-lo, ainda que, para tanto, tenham algum custo, como relatado:

Tudo o que for pra ajudar a empresa a crescer sempre se torna viável, tudo que percebemos que é novo e ajuda o negócio a melhorar e a crescer, tentamos ao máximo incorporar no dia a dia, por mais que isso tenha algum custo. Para isso usamos os cálculos das aulas, para ver quanto tempo iremos levar para recuperar o investimento e se realmente compensa (Entrevistado 1).

A viabilidade de aplicação e exploração dos conhecimentos adquiridos, assimilados e transformados é clara para os entrevistados, pois, o conhecimento que traz a possibilidade de alguma mudança, que, quando realizada corretamente, reflita de maneira positiva no futuro da empresa, é exequível e incorporável. Além disso, são incorporados, sobretudo, os conhecimentos sobre o que não deve ser feito no ambiente organizacional, como por exemplo, pontos falhos repassados por meio do curso.

Assim, os empreendedores entrevistados aplicaram conhecimentos obtidos por meio da capacitação empreendedora em suas empresas, sobretudo aqueles que foram considerados de maior viabilidade, para melhorar suas competências organizacionais. Neste sentido, foram relatados como os principais conhecimentos explorados: administração financeira, gestão de pessoas, e marketing empresarial.

\section{CONSIDERAÇÕES FINAIS}

A capacidade absortiva consiste em diversas atividades que compõem a rotina de uma organização e procedimentos por meio dos quais a empresa adquire, assimila, transforma e explora o conhecimento interno e externo à firma, buscando inovações e vantagens competitivas. Assim, cada atividade possui uma proposta diferente, mas que se complementam (OLIVEIRA, 2016).

Ao analisar cada uma das fases da capacidade de absorção dos empreendedores ao realizarem cursos de capacitação empresarial, foi possível responder o principal objetivo deste estudo, por meio da compreensão do relacionamento existente entre a capacitação profissional e a capacidade absortiva dos empreendedores, que ocorre quando estes conseguem absorver o conteúdo passado no curso de capacitação Bom Negócio e aplicá-lo, visando melhorias organizacionais nas suas atividades.

Desse modo, no estudo, analisou-se como ocorre a assimilação e internalização do conhecimento adquirido por meio de cursos; verificando-se, dessa forma, que as informações recebidas são compreendidas e identificadas na prática e na rotina da empresa, tornando-se fácil e viável a sua incorporação, ou seja, os conhecimentos são utilizáveis não apenas na teoria, como também podem ser visualizados nos hábitos empresariais.

Pode-se perceber que ocorre a transformação e combinação do conhecimento existente com 0 conhecimento adquirido por meio da capacitação, ou seja, o conhecimento interno à organização e o conhecimento externo, advindo da capacitação profissional. Isso ocorre, normalmente, quando os empreendedores visualizam a importância do assunto proposto para a melhoria do estabelecimento e de seus produtos ou serviços e se dispõem a modificar suas atividades. Assim, a transformação do conhecimento se ajusta como uma combinação daquilo que os empreendedores já tinham por certo e as informações sugeridas pelo curso de capacitação. 
Assim, é visível a presença desta capacidade dinâmica nos empreendedores considerando que estes conseguem, após a aquisição do conhecimento, assimilá-lo, transformá-lo e explorá-lo sem dificuldades. A educação empreendedora é vista, pelos empreendedores, como ponto positivo à organização, os quais, em sua maioria, incentivam os seus funcionários a realizá-los, para que melhorem suas funções dentro da organização e assim ofereçam um melhor serviço. Nesse sentido, é evidente que os empreendedores consideram viável a aplicação dos novos conhecimentos adquiridos, sempre que estes venham a agregar os conhecimentos já existentes na empresa e melhorar seus recursos e vantagem competitiva.

Esta pesquisa possibilitou a visualização da importância presente na capacidade absortiva dos empresários que participam de cursos de qualificação empresarial, considerando que é uma capacidade, por vezes, pouco explorada no meio empresarial, e que, por meio desta, os empreendedores conseguem implementar novos conhecimentos em suas empresas, melhorando o oferecimento de seus serviços e produtos aos consumidores, e deste modo, também aumentando sua competitividade e lucratividade.

Como limitação do estudo pode ser mencionada a falta de interesse de alunos do curso de capacitação em serem entrevistados, restringindo a pesquisa a apenas quatro pesquisados. De tal modo, como sugestão para estudos futuros, recomenda-se a ampliação do estudo, com mais entrevistados e observação direta nas organizações em que os proprietários participaram do curso, objetivando a identificação mais precisa da capacidade de absorção dos empreendedores.

\section{REFERÊNCIAS}

ARAÚJ O, L. F. S. et al. Diário de pesquisa e suas potencialidades na pesquisa qualitativa em saúde. Rev. Bras. Pesq. Saúde. Vitória, v. 15, n. 3, p. 53-61, 2013

BARDIN, L. Análise de Conteúdo. São Paulo: Edições 70, 2011.

BARNEY, J. B. Firm resources and sustained competitive advantage. J ournal of Management, v. 07, n. 1, p. 99-120, 1991.

BARRETO, A. A. Informação e transferência de tecnologia: mecanismos de absorção de novas tecnologias. Brasília: IBICT, 1992.

BREZNIK, L.; HISRICH, R. D. Dynamic capabilities vs. Innovation Capability: are they related? Journal of Small Business and Enterprise Development, v. 21, n. 3, p. 368-384, 2014.

CARLOMAGNO, M. C. ROCHA, L. C. Como criar e classificar categorias para fazer análise de conteúdo: uma questão metodológica. Revista Eletrônica de Ciência Política, v. 7, n. 1, p. 173-188, 2016.

CIELO, I. D. Perfil empreendedor: uma investigação das características empreendedoras nas empresas de pequena dimensão. In: PREVIDELLI, J. . .; SELA, V. M. (org.). Empreendedorismo e educação empreendedora. Maringá: UNICORPORE, 2006. cap. 8.

CRUZ, R.; FORNER, C.; LIBERMANN, N. M. L. Perfil de pequenas empresas brasileiras atendidas pelo programa EMPRETEC do Sebrae e seus empreendedores. In: PREVIDELLI, J. J.; SELA, V. M. (org.). Empreendedorismo e educação empreendedora. Maringá: UNICORPORE, 2006. p. 175-198.

\section{CRUZ, M. A. Mensuração da capacidade absortiva dos parceiros industriais}

da Cemig: implicações para inovação no setor elétrico. 2011. Dissertação (Mestrado em Administração de Empresas) - Pontifícia Universidade Católica de Minas Gerais, Belo Horizonte, 2011

DRUCKER, Peter Ferdinand. Innovation and Entrepreneurship. New York: Harper \& Row, 1985.

DUARTE, R. Entrevistas em pesquisas qualitativas. Curitiba: UFPR, 2004. 
ESCOBAR, M. A. R. Relação das CapacidadesDinâmicas e Orientação Empreendedora com o Desempenho em Agências de Viagens moderada pelo Ambiente Organizacional. 2012.Tese (Doutorado em Administração e Turismo) - Programa de Pós-Graduação em Administração e Turismo, Universidade do Vale do Itajaí, Biguaçu, 2012.

FLICK, U. Introdução à pesquisa qualitativa. Porto Alegre: Artmed, 2009

GAEBLER, D. M. A capacidade de absorção no desenvolvimento de produtos de moda: proposição de melhorias ao desenvolvimento de produtos da bograntex. 2015. Dissertação (Mestrado Profissional em Administração) - Centro de Ciências da Administração e Socioeconômicas , Universidade do Estado de Santa Catarina, Florianópolis, 2015.

GODOI, C. K.; MATTOS, P. L. C. L. Entrevista qualitativa: instrumento de pesquisa e evento dialógico. In: SILVA A. B.; GODOI, C. K.; BANDEIRA-DE-MELO, R. (org.). Pesquisa qualitativa em estudos organizacionais: paradigmas, estratégias e métodos. 2. ed. São Paulo: Saraiva, 2010. p. 301-323.

GODOY, A. S. Introdução à pesquisa qualitativa e suas possibilidades. Revista de administração de Empresas, São Paulo, v. 35, n. 2, p. 57-63, 1995.

KAEHLER, C. et al. Relationship between Adaptive Capability and Strategic Orientation: An Empirical Study in a Brazilian Company. iBusiness, v. 6, p. 1-9, 2014.

LAZZAROTTI, F. et al. Orientação empreendedora: um estudo das dimensões e sua relação com desempenho em empresas graduadas. Revista de Administração Contemporânea, v. 19, n. 6, p. 673-695, 2015

MEIRELLES, D. S.; CAMARGO, A. A. B. Capacidades Dinâmicas: 0 Que São e Como Identificá-las? Revista de Administração Contemporânea, Rio de Janeiro, v. 18, Edição Especial, art 3, p. 41-64, 2014.

MENDES, M. T. T. Educação Empreendedora: uma visão holística do empreendedorismo na educação. 2011. Dissertação (Mestrado em Ciências da Educação) Universidade Católica Portuguesa, Lisboa, 2011

OLIVEIRA, D. M. L. Mensuração da capacidade absortiva: Proposta e validação de fatores de mensuração para organizações intensivas em conhecimento de Minas Gerais. 2016. Dissertação (Mestrado Acadêmico em Administração) - Programa de Pós-Graduação em Administração, Pontifícia Universidade Católica de Minas Gerais, Belo Horizonte: 2016

OLIVEIRA, S. L. Tratado de metodologia científica: projetos de pesquisa, TGI, TCC, monografias, dissertações e teses. São Paulo: Pioneira, 1997.

PREVIDELLI, J . J .; SELA, V. M. Empreendedorismo e educação empreendedora. Maringá: UNICORPORE, 2006.

PICOLI, F. R.; TAKAHASHI, A. R. W. Capacidade de Absorção, Integração Social e Aprendizagem Organizacional: um estudo em Instituições de Ensino Público de Curitiba - PR. In: ENCONTRO DE ESTUDOS EM ESTRATÉGIA, 6., 2013, Bento Gonçalves. Anais da ANPAD. Bento Gonçalves: ANPAD, 2013.

SALES, A. H. L.; SOUZA NETO, S. P. Empreendedorismo nas micro e pequenas empresas brasileiras. In: PREVIDELLI, J. J.; SELA, V. M. (org.). Empreendedorismo e educação empreendedora. Maringá: UNICORPORE, 2006. p. 101-116.

SCHAEFER, R.; MINELLO, I. F. Educação empreendedora: premissas, objetivos e metodologias. Revista Pensamento Contemporâneo em Administração, v. 10, n. 3, p. 60-81, 2016.

SCHLEIMER, S. C.; PEDERSEN, T. The Driving Forces of Subsidiary Absorptive Capacity. J ournal of Management Studies, v. 50, n. 4, p. 646-672, 2013 
SILVA, C. R. GOBBI, B. C. SIMÃO, A. A. O uso da análise de conteúdo como uma ferramenta para a pesquisa qualitativa: descrição e aplicação do método. Revista Organizações Rurais \& Agroindustriais, v. 7, n. 1, p. 70-81, 2005.

TEECE, D. J.; PISANO, G.; SHUEN, A. Dynamic Capabilities and Strategic Management. Strategic Management Journal, v. 18, n. 7, p. 509-533, 1997.

TEIXEIRA, C. M. M. Educação para o Empreendedorismo: um estudo sobre o Projeto Nacional de Educação para o Empreendedorismo. 2012. Dissertação (Mestrado em Intervenção Social, Inovação e Empreendedorismo) - Faculdade de Psicologia e de Ciências da Educação, Faculdade de Economia, Coimbra: 2012.

URIARTE, L. R. et al. Empresário ou Empreendedor? In: ENCONTRO DE ESTUDOS SOBRE EM PREENDEDORISMO E GESTÃO DE PEQUENAS EM PRESAS, 38., 2000, Maringá. Anais [...]. Maringá: ABEPRO, 2000.

VALLADARES, P. S. D. A.; VASCONCELLOS, M. A.; DI SERIO, L. C. Capacidade de Inovação: Revisão Sistemática da Literatura. Revista de Administração Contemporânea, v. 18, n. 5, p. 598-626, 2014.

WANG, C. L.; AHMED, P. K. Dynamic capabilities: A review and research agenda. International J ournal of Management Reviews, v. 9, n. 1, p. 31-51, 2007.

WERNERFELT, B. A resource-based view of firm. Strategic Management J ournal, v. 5, n. 2, p. 171-180, 1984.

ZAHRA, S. A.; GEORGE, G. Absorptive Capacity: A review reconceptualization, and extension. Academy of Management Review, v. 27, n. 2, p. 185-203, 2002. 


\section{APÊNDICE A - ROTEIRO DE ENTREVISTA SEMIESTRUTURADA}

a) Quantas pessoas atuam na empresa? Quais os cargos?

b) A empresa valoriza as atitudes que promovem mudanças internas? Como e quais?

c) A empresa busca constantemente informações externas relevantes para seu negócio? Onde busca e quais informações?

d) A empresa investe em atividades de pesquisa e desenvolvimento? Quais?

e) Os funcionários possuem qualificação adequada para o desenvolvimento de suas funções? E os gerentes?

f) Os integrantes da empresa (empresários e funcionários) são incentivados pela empresa a participar de treinamentos e cursos de aperfeiçoamento profissional? Com que frequência?

g) A cultura organizacional da empresa é aberta a mudanças em suas atividades ou prefere manter-se sempre trabalhando da mesma forma? Por quê?

h) A empresa já se baseou em conhecimentos provenientes de outras empresas do mesmo ramo?

i) Os conhecimentos repassados por meio do curso de capacitação são facilmente identificados e visualizados na prática, ou são conhecimentos bons apenas na teoria? Por quê?

j) O conhecimento adquirido por um dos integrantes da empresa é compartilhado com os demais? Como?

k) As informações são repassadas facilmente mesmo entre chefe e funcionário? Como ocorre esse repasse?

I) Os conhecimentos obtidos em cursos de capacitação, como, por exemplo, os conhecimentos em finanças, marketing, gestão de pessoas, podem ser incorporados aos conhecimentos já existentes na empresa e transformados num novo conhecimento? Como isso acontece?

m) Você acredita que o conhecimento obtido por meio do curso de capacitação auxilia na inovação e melhoria nos produtos e serviços da empresa? Por quê?

n) Com relação à aplicação, na sua opinião, os novos conhecimentos adquiridos por meio de cursos de capacitação são aplicáveis à empresa ou não? Por quê?

o) Se o conhecimento for aplicável em sua empresa, seria VIÁVEL aplicá-lo? Ou seja, teria um bom retorno custo-benefício? Por quê?

p) Você aplicou algum conhecimento obtido por meio do curso em sua empresa? Qual? 